\title{
Strategies for Managing Excess and Dead Inventories: A Case Study of Spare Parts Inventories in the Elevator Equipment Industry
}

\author{
Oguji Nnamdi \\ $\mathrm{PhD}$ International Business and Marketing \\ University of Vaasa, Wolffintie 34, 65200 Vaasa, Finland \\ Email: nnamdi.oguji@gmail.com
}

\begin{abstract}
Spare parts organizations of elevator original equipment manufacturers (OEM) face enormous challenges on how to manage their excess and dead inventory due to the life-cycle of the equipment. On one hand, the long life-cycle of equipment's requires that organizations ensure the provision and availability of the spares until equipment termination / retirement. On the other hand, these organizations need to control their inventory carrying cost, inventory write-offs and ensure that only needed spare parts are available for their customers. This study explores operations and inventory strategies for reducing and controlling excess inventory. Through a combination of literature review, root cause analysis and the implementation of these strategies in a case company, a managerial tool-box for managing and controlling excess inventory was developed. Root causes of excess inventory were shown to be due to data errors in inventory planning parameters, inappropriate demand forecasting methods, lack of ownership, lack of part life-cycle management and part lifecycle pricing as well as internal practices within the organizations. The paper proposes managerial tool-box that includes both Strategic (ownership and key performance indicators, strategic policy on reverse logistics, customer buybacks, large purchase volumes for sourcing savings, leveraging Big Data and Analytics); Reactive (lateral transshipment, scraping \& disposal of excess inventory, sales discounts, spare parts dismantling into sub spare parts) and Proactive (Croston/SBA forecasting, exception management for data errors, tool/algorithm for new spare parts forecasting, part replacement control measures, forecasting sudden decrease in demand and part life-cycle pricing) measures on how excess inventory can be controlled and reduced.
\end{abstract}

Keywords: inventory control, inventory management, excess inventory, dead inventory, elevator industry, spare parts

\section{INTRODUCTION}

Excess inventories as the name implies are Stock Keeping Units (SKU's) that has a significant amount of inventories on-hand compared to average annual consumption. Dead inventories are SKU's that are nonmoving for several years. Spare parts organizations of original equipment manufacturers in the elevator industry face enormous challenges on how to manage their excess and dead inventory due to the life-cycle of the equipment. On one hand, the long life-cycle of these equipment's requires that these organizations ensure the provision and availability of the spares until equipment termination/retirement. On the other hand, these organizations need to control their inventory carrying cost and inventory write-offs and ensure that only needed spare parts are available for their customers. The introduction of new equipment's and new spare parts, the modernization of existing equipment's and the increasing pirating of spare parts and entry of third-party spare parts providers increases the complexity of managing excess and dead inventory.

The reasons for excess inventories for spare parts organizations have been studied extensively in the literature. For example, van Jaarsveld and Dekker (2011) suggest that excess and dead inventories are as a result of changing maintenance policy on the original equipment's, the use of alternative spare parts; the introduction of new spare parts and temporarily/permanent demand variations. Tersine and Toelle (1984) suggest that forecast errors, overzealous purchase practices, new technological innovations and a reduction in the demand for a spare part are the reason for excess and dead inventory. Brown et al. (1964) suggest that when the function served by the equipment is no longer required, there is the likelihood of excess inventory. Crandall and Crandall (2003) suggest that internal practices within the organization such as design changes and new product introduction, as well as internal practices of the sales and marketing department in an attempt to create special/safety inventories for key customers create excess inventories.

There are two streams of existing studies focused on managing excess and dead inventory. The first stream of studies are studies that propose reactive strategies such as the scrapping of excess inventories, disposal at discount prices to suppliers and customers (e.g., Tersine \& Toelle, 1984; Rosenfield, 1989), and lateral transshipment policies (Paterson et al., 2009; Zhao, Wu, Liang \& Dolgui, 2016). The second stream of studies are proactive studies linking equipment maintenance and spare parts demand planning (e.g., Sarker \& Haque, 2000; Thormann, 2015; Poppe, Basten, Boute \& Lambrecht, 2017), and studies focusing on exponentially decreasing order quantities and safety stocks over time for items that are in high risks of obsolescence; or items with knowledge of the probability of obsolescence (Song \& Zipkin, 1996; Cobbart \& van Oudheusden, 1996; Song \& Lau, 2004; Prince \& Dekker, 2011; van Jaarsveld \& Dekker, 2011).

These studies provide contributions on the management of dead and excess inventory, but their applicability in real life organization has not been validated. 
First, why these studies are fragmented studies (with exception to Crandall \& Crandall, 2003) addressing a single strategy to managing excess and dead inventories, they also do not link the root causes to the management of the respective excess inventories. Second, existing studies are either insufficient and non-exhaustive in providing a managerial toolbox for managing excess, and dead inventory or they do not provide a context-specific knowledge for managing excess and dead inventory especially for spare parts organization in the elevator industry. Third, existing studies on managing excess inventory mostly utilized mathematical optimization models that are difficult to obtain the data in practice. While the limited use of case study research in logistics and supply chain has been documented (e.g. Kennedy et al., 2002), it is believed that case studies are more legitimate method in logistics inquiries (Aastrup \& Halldorsson, 2008) as they provide nuanced view on reality" and produce context-dependent knowledge (Flyvbjerg, 2006).

To this end, it is pertinent to say that excess, and dead stock inventory has not been studied for the elevator industry. To the best of found knowledge, some studies have studied spare parts management for original equipment manufacturers and service providers in different industries but not in the elevator industry. A comprehensive descriptive study by Crandall and Crandall (2003) addresses excess inventory generically without specifics to the industry. Spare parts management in the elevator industry is different from other industries such as aerospace, automotive, military, and IT sectors where some case studies have been done. The lifecycle of elevator industry is longer compared to these industries. Passenger flight has an estimated life-cycle of 30 years after which they are terminated (Lyte, Flexport Report). However, when elevators are retired or terminated at the end of their life-cycle, they are modernized, and spare parts availability is still guaranteed. Thus, the decision of what and how much spare parts to keep in the inventory is a very challenging task for the elevator industry.

The objective of this study is to explore literature on strategies for managing excess and dead inventory for spare parts and apply it to a case study of a spare parts department of a multinational elevator equipment manufacturer and service provider. Through the case study, a managerial toolbox for managing and reducing excess and dead inventory for spare parts organization in the elevator industry is developed to aid managerial decision for spare parts inventory in the elevator industry. This paper makes two remarkable contributions. First, it contributes to research on multi-local and multi-echelon supply chains and spare parts optimization (Porras \& Dekker, 2008; Jaarsveld \& Dekker, 2011; Tiacci \& Saetta, 2011; Thormann, 2015; Zhao et al., 2016; Nakandala, Lau \& Shum, 2017) by extending the literature to the context of elevator industry. Second, it bridges the gap between research and practice by testing and applying theories developed in supply chain and inventory optimization literature in solving excess stock challenges in a case company. Consequently, the study enjoins researchers that have identified gaps between research and practice in supply chain management (e.g., Sweeney, Grant \& Mangan, 2015) in their call for research relevance and research with impact on practice (Botter \& Fortuin, 2000; Stuart et al., 2002; Harrison, Lee \& Neale, 2004; Jouni et al., 2011).

\section{LITERATURE REVIEW}

To carry out a literature review on excess and dead inventory, six databases (WILEY, EBSCO, PROQUEST, Science Direct; EMERALD; Taylor \& Francis) was explored with the abstract search for "excess/dead" and "spare parts"; OR "obsolescence and spare parts" OR "obsolete and spare parts". "Spare parts" is included in the search criteria to ensure that only articles focused on or applicable to spare parts inventory management are retrieved. This is because spare parts inventory is different, and are driven by equipment maintenance policy compared to other manufacturing/WIP inventories, which are driven by production processes and customer demands (Kennedy, Patterson \& Fredendall, 2002; Porras \& Dekker, 2008).

In this paper, one specific aspect of obsolescence or obsolete inventory is considered. The focus is not on obsolescence, i.e., Diminishing Manufacturing Sources and Material Shortages (DMSMS) (Sandborn, 2013) per se, but the excess inventory it creates due to the introduction of new alternative spare parts. DMSMS is caused by the unavailability of technologies or part (Sandborn, 2013). Often, new alternative spare parts are introduced to the offering, shifting demand to the new spare parts leading to cannibalization of the existing obsolete spares (Srinivasan, Ramakrishnan \& Grasman, 2005) and thus causes excess inventory for the obsolete spare parts.

The literature review below emphasizes relevant studies on managing excess and dead spare parts inventory or at least applicable to the purpose and aim of this study. Some generic supply chain strategies, VMI, CPFR, QRS, and ECR, are not discussed in this paper because they are not at the core of excess inventory management especially in elevator spare parts business but more related to improving customer satisfaction.

\subsection{Management of Excess Inventory}

\subsubsection{Forecasting the Sudden Decrease in Demand or} Obsolescence

The traditional approach to obsolescence is to add a cost component to the holding cost in the lot-sizing model (See Naddor, 1966; Tersine, 1988; Masters, 1991; Silver et al., 1998; Cobbaert \& van Oudheusden, 1996). This approach assumes that inculcating the obsolescence cost to lot sizing inevitably considers the cost of obsolescence. On one hand, obsolescence cost and inventory holding cost are different from each other. On the other hand, obsolescence costs incur only at a single point in time while holding cost incurs over a specified time interval (Hadley \& Whitin, 1963). Thus, these two costs are different and should not be combined as assumed in the traditional approach. For this reason, recent authors have focused on using mathematical models to forecast obsolescence or the sudden decrease in demand as an appropriate way to deal with the problem of obsolescence. This is because if it is known in advance that there will be a decrease in demand leading to a risk of obsolescence, it is often easier to adjust inventory planning models accordingly before the decrease in demand occurs thereby eliminating the risk of excess inventory than the traditional approach of combining the cost of obsolescence and inventory holding cost. 
For example, Cobbart and Oudheusden (1996) proposed Economic Order Quantity (EOQ) for fast moving items subject to sudden death obsolescence. The model incorporates economic order quantities for three scenarios'. First, when the risk of obsolescence for the items remains constant, and no shortage is allowed. Second, when there are different obsolescence risks, and shortage is not allowed. Finally when there are different obsolescence risks, and shortages are allowed. The model suggests that if the probability of obsolescence is given beforehand for example by an expert for a particular period, incorporating this probability of obsolescence in the economic order quantity could reduce the economic order quantity over time thereby reduces the cost of obsolescence and the quantity of stock available on hand before the sudden obsolescence.

Similarly, Prince and Dekker (2011) studied the inventory model for slow moving parts subject to obsolescence. The study found that if known in advance there will be a decrease in demand leading to a reduction in re-order point (ROP), a shift in control policy geared towards a reduction in EOQ and ROP before the decrease in demand occurs could take away the excess stock. This is because the advance change in control policy will make it possible for subsequent demand after the policy change to take away the excess stock before the final demand decrease. Expert opinion or dynamic programming was suggested to be used to determine when the sudden decrease in demand will occur.

The above studies require some expert knowledge of the distribution of time at which the part becomes obsolete. Spare parts inventory is intermittent, and the life-cycle of equipment is very long, and the exact knowledge of equipment failure is difficult to obtain. As a result, it is often very challenging to forecast when the risks of obsolescence will occur. Some studies have made attempts on this. For example, Jaarsveld and Dekker, (2011) estimated the risks of sudden death of obsolescence or sudden decrease in demand using historical demand data. There model use the Markov chain process to estimate the probability of obsolescence using the number of sales orders within a period and the probability that spare parts with a given number of sales orders will have zero demand in a subsequent period. Based on this estimate, they derive the cost estimates (holding cost, ordering cost, shortage cost, and obsolescence cost) for different base stock levels (Re-order points). Their model recommends the base stock level with the minimal total cost for SKU's with risks of sudden death of obsolescence. Similar historical data is used in Sandborn and Ahmad (2011) to forecast the risks of obsolescence. However, their historical data focuses on using data on previous obsolescence provided by supplier/OEM to forecast future obsolescence. Teunter, Syntetos, and Babai (2011) tackle the problem of sudden decrease in demand for slow-moving items by using a new intermittent forecasting method that provides no forecast values after several periods of no demand.

The summary of this studies suggests that with adequate information about a potential decrease in demand, either via historical data or expert opinion, it is possible to change the ordering policy (EOQ/ROP) and forecast parameters of the spare parts and thus proactively reduce the risks of excess and dead inventory.

\subsubsection{Lateral Transhipment Policies}

Lateral transshipment is a process in which spare parts can be moved from one location with excess inventory to another location, at the same echelon, where there is no excess inventory, with the aim of reducing supply delays of spare parts (Tiacci \& Saetta, 2011). Lateral transshipment is one way for optimizing the multi-echelon logistics network. It involves replenishing several networks or nodes from other networks within the same echelon logistics networks (Olsson, 2010). This strategy enables the organization to optimize the logistic network by minimizing total inventory cost, satisfying customer service levels and reducing stockout risks (Zhao et al., 2016; Nakandala, Lau \& Shum, 2017).

Two main streams of literature on lateral transshipments can be identified. The first refers to proactive transshipment models where lateral transshipments are used to redistribute stock amongst all stocking points in an echelon at predetermined moments in time (Paterson et al., 2009). In this case, lateral transshipment decisions are organized in advance such that the handling costs are as low as possible. The second stream of literature refers to reactive transshipments which are scheduled to take place at predetermined times before all demand is realized, or they can take place at any time to respond to stock-outs or potential stock-outs (Paterson et al., 2009).

Overall, to reduce excess inventory for spare parts especially involving multi-location warehouse of a global spare parts distribution chain, an introduction of lateral transshipment policy is essential for excess inventory reduction. As the literature points, in addition to excess and dead inventory reduction, lateral transshipment also increases customer service levels while reducing backorder cost and inventory holding cost.

\subsubsection{Optimization of Maintenance and Spare Provisioning Policy}

Overall, to reduce excess inventory for spare parts especially involving multi-location warehouse of a global spare parts distribution chain, an introduction of lateral transshipment policy is essential for excess inventory reduction. As the literature points, in addition to excess and dead inventory reduction, lateral transshipment also increases customer service levels while reducing backorder cost and inventory holding cost.

Thormann (2015) suggest that by integrating real-time status information about equipment utilization and service conditions, optimal spare parts stocking strategies can be determined. The determination of these optimal strategies must be designed based on type of maintenance services, preventive or corrective maintenance (Sarker \& Haque, 2000; Wang \& Syntetos, 2011; Poppe et al., 2017; Keizer, Teunter \& Veldman, 2017). While corrective maintenance is performed when a component breaks down and needs replacements, preventive maintenance can be planned on a periodic basis (periodic maintenance), or it can be triggered by a monitored condition-based maintenance (Poppe et al., 2017).

Most studies linking maintenance and inventory planning policy that address excess inventory reduction have focused on preventive maintenance. They argue that preventive maintenance increases the total demand for spare parts compared to corrective maintenance, and the advance demand information is used to plan spare parts demands in 
advance (Poppe, Basten, Boute \& Lambrecht, 2017). Sarker and Haque (2000) studied how block replacement preventive maintenance and continuous review inventory policy jointly reduces maintenance and spare parts cost compared to separately or sequentially carrying out these optimized policies. By block replacement, they entail a preventive maintenance policy where many identical, low-cost items (e.g., screws, springs, coils, disks, valves, bearings, bushings, etc.) are replaced group-wise after certain time intervals. Their model shows that jointly optimized policy produces better results than separately or sequentially optimized policies.

Keizer, Teunter and Veldman (2017) studied the joint optimization of condition-based maintenance and spare parts planning for multi-component systems. They showed significant savings could be obtained by basing both the maintenance decisions and the timing of ordering spare parts components on the system's condition. Zahedi-Hosseinia, Scarf and Syntetos (2017) studied joint optimization of planned periodic inspection maintenance and spare parts provisioning by comparing periodic review and continuous review replenishment policies. They found that periodic review policy with ordering that is twice as frequent as the inspection is cost optimal in the context of a papermaking plant. Using a simulation study, Poppe, Basten, Boute and Lambrecht (2017) showed that by using advance demand information in managing the spare part inventory, inventories and their related cost could even be lower for condition-based maintenance compared to corrective maintenance, provided that the advance demand information is used appropriately when managing inventories. Wang and Syntetos (2011) utilize delay time modeling for maintenance to forecast the demand for spare parts based on the requirements for both corrective and preventive maintenance. They studied how maintenance policy can jointly be optimized with inventory planning by linking the forecasting of the equipment maintenance to spare parts demand. They argued that by forecasting demand that relies on the very sources of the demand generation process (i.e., equipment maintenance), using delay time modeling approach, maintenance cost and spare parts inventory cost can be jointly optimized.

In summary, it is generally accepted that one of the probable benefits of condition-based maintenance (CBM) or advance demand information from preventive maintenance is the expected decrease in inventory (excess inventory) as the procurement of parts can be triggered by the identification of a potential failure. (Louit, Pascual, Banjevic \& Jardine, 2011; Poppe, Basten, Boute \& Lambrecht, 2017; Zahedi-Hosseinia, Scarf \& Syntetos, 2017). It is believed that firms that link their CBM to their inventory planning policy can reduce excess inventory and optimize both maintenance and inventory related cost.

\subsubsection{Sales Discount \& Scrapping for Excess Inventory}

Spare parts excess and dead inventory can be disposed or scrapped from the inventory or sold at sales discount. Song and Zipkin (1996) propose that organizations should have a disposal policy for excess inventories. According to them, having such a disposal policy for excess inventory either directly or through price promotions make the problems of obsolescence more manageable. Crandall and Crandall (2003) suggest that disposal of excess and dead inventory must be matched with the type of inventory. In a typical spare parts inventory in the elevator industry, there are different categories of materials such as electrical components, PCB's, mechanical components, and spare parts made from recyclable materials such as aluminum, plastics, etc. Recyclable excess spare parts can be disposed to recycling companies. Some spare parts for example assemblies, kits can be modified or dismantled to smaller components that are fast moving spare parts. Commercial spare parts can be sold to suppliers or other industries at discounted prices. Finally, excess inventory can be scrapped and disposed of the inventory.

It is often the case that scrapping excess and dead stock inventory decreases the stock value of the company and are recorded as losses. However, this action reduces warehouse cost. In some cases, the cost of keeping this inventory in the warehouse may outweigh the actual value of the spare parts. For this reason, studies are estimating how much excess inventory to dispose of or at a salvage value and how much to retain (Anthony, 1973; Toelle \& Tersine, 1984; Toelle \& Tersine, 1992; Silver \& Willoughby, 1999). The general assumption of this studies is that if some inventory is liquidated or disposed of, holding costs will be reduced and some immediate salvage revenue may be realized from the liquidation/disposal of the excess items.

\subsubsection{Applying Appropriate Forecasting Models}

Demand forecasting plays a significant role in inventory planning and excess inventory reduction. Accurate forecasting makes it possible to meet customer service levels, manage inventory levels in warehouses and maintain accurate inventory policies necessary to minimize excess stocks and warehouse space. The literature has established several forecasting models for various demand patterns. Time series and casual methods are usually employed for quantitative methods while Delphi method is mostly utilized for qualitative models. Time series models such as naïve method, moving average, weight moving average, exponential smoothing, Croston, bootstrapping, seasonality analysis, multiplicative decomposition and additive decomposition have been suggested to use for different demand patterns.

To manage excess inventory, is it imperative that the spare parts department must understand the different categories of spare parts and their demand pattern and forecast them accordingly (Syntetos, Boylan \& Croston, 2005). For example, it has been shown that items with intermittent demand significantly ends up as obsolescence or excess inventory than fast moving items (Syntetos \& Boylan, 2005, 2006; Teunter et al., 2011). As a result, it is recommended to use the appropriate forecasting method such as Croston or modified Croston known as the Syntetos \& Boylan approximation (SBA) (Syntetos \& Boylan 2005, 2006; Syntetos, Babai, Dallery \& Teunter, 2009) for forecasting this type of items. Intermittent demand is a peculiar and challenging demanding pattern in spare parts as there are many spare parts with several months/periods of no demand in-between months of demand. The size of demand can vary in size in a period, with some periods showing no demand, other periods showing erratic or lumpy demand (Teunter et al., 2011). This type of demand is difficult to predict, and errors in prediction are usually costly because it creates excess inventory. 
There are several reasons why it makes sense to use different forecasting method for different categories of spare parts. First, theoretically, it has been shown that forecast models perform better than the other depending on the demand pattern and the nature of the item been forecasted (Swanson et al., 2011). Also, in a typical spare parts organization, there may be customized spare parts for a limited volume of unique equipment's installed or in service. Certain spare parts may have very long life-cycle before failure, for example, drive stations, etc. Some elevator spare parts like batteries, push buttons, LED lights may require replacements within two years intervals. Applying same forecasting model or approach to the different categories of spare parts will lead to excess inventory. For these reasons, the nature of the spare parts should be considered when applying a suitable forecasting model.

\section{RESEARCH DESIGN}

Case-based action research was selected as the suitable research methodology for this study because this paper aims to develop a managerial model of managing and reducing excess spare parts inventory for the case company. Research method should be selected based on the aim of the research, in this case, a managerial focus, which a case-based action research is well suited for. The case company wanted practical ways to reduce their excess inventory and as such the implementability of the developed model is of highest priority. Furthermore, the case company needed strategies and appropriate actions that can reduce the current stockpile of excess inventory. It has been suggested that mathematical models are not always suitable for spare parts (e.g. Botter $\&$ Fortuin, 2000; Jouni et al., 2011). Consequently, researchers have called for case study approach as a more suitable method (Stuart et al., 2002). In addition, the nature of the research problem "managing and reducing excess stock", requires multiple thematic perspective and multiple unit of analysis which makes a case study appropriate for such settings. The use of case-based action research allows the researcher to understand the application environment and helps the researcher to develop the model iteratively with the managers thus providing effective heuristic rules (Jouni et al., 2011).

The case study is a spare parts department of a multinational elevator equipment manufacturer and service provider. The elevator industry consists of four largest global players such as Otis, Schindler, Thyssen, and KONE. The current case study is one of the largest elevator companies and its distribution chain is shown in Figure 1. The case company has three distribution centers in Singapore to serve the Asia Pacific subsidiaries, China for Chinese subsidiary and Germany for Europe, Africa, and Middle East Subsidiaries. Their customers include both the company subsidiaries, licensed distributors and other spare parts resellers and competing global elevator equipment manufacturers. The company currently has weekly consolidation of SKU's in each distribution center for SKU's that are replenished from one distribution center to the other. The consolidation is to take advantage of economies of scale by saving cost because it costs less to ship a full truckload than individual shipments. Third-party logistics providers operate the three distribution centers, and it allows the case company to consolidate all suppliers' deliveries within a specific region in a central warehouse before replenishing to other locations. As there are many suppliers, especially in China and Asia-Pacific that don't have all the required export certifications and licenses, the warehouse and the

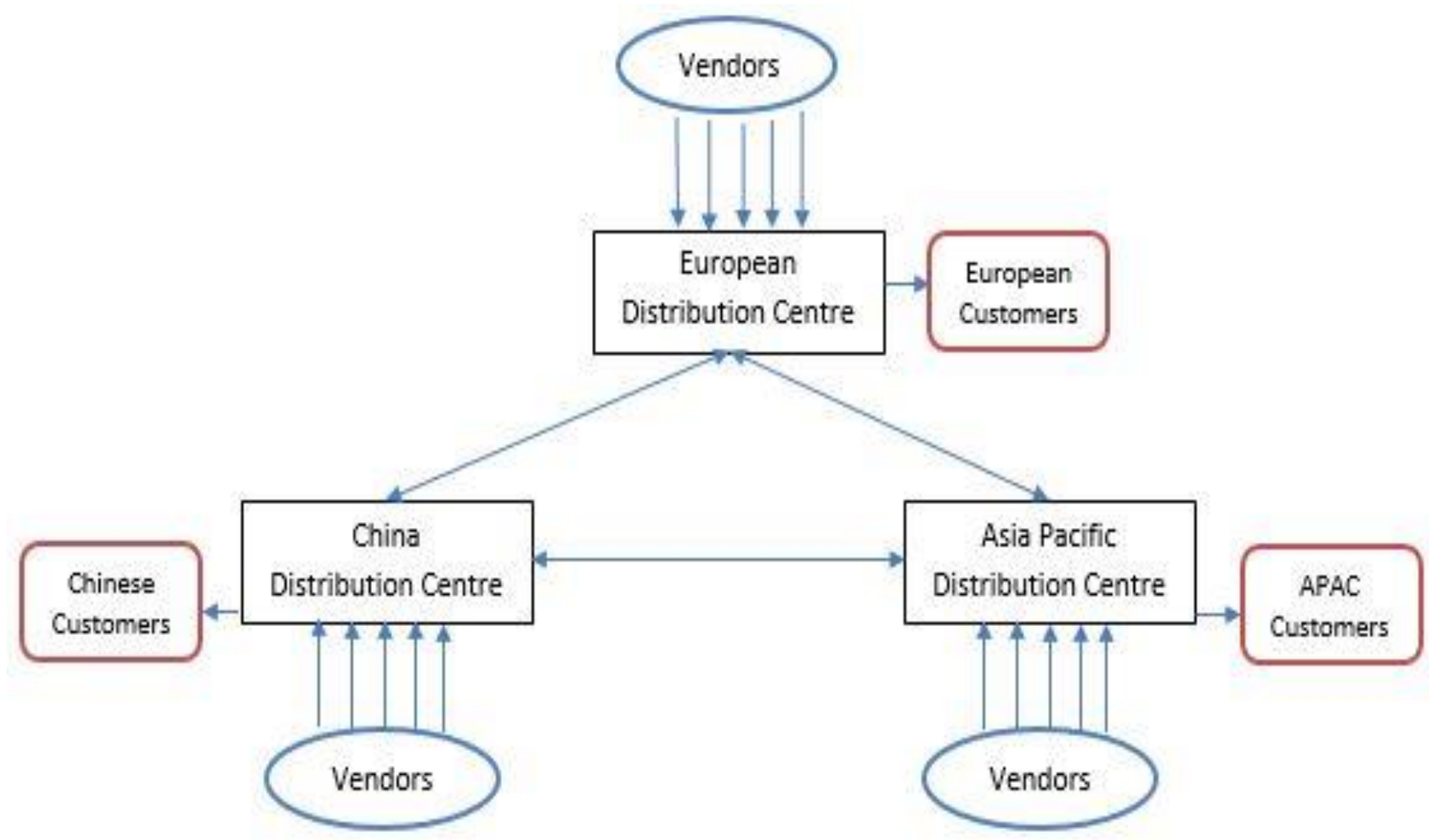

Figure 1 The company's distribution chain \& replenishment 
distribution chain allows the company to use their brand and license to distribute these materials globally.

The subsidiaries have their proximity stock or van sock and in some cases, own small storage locations. The typical structure of the case company distribution chain is shown above. Due to growth in the company, pressure to reduce inventory carrying cost, excess inventory and ensure that only the right spare parts are kept in inventory, the company wants to understand how to reduce their excess inventory and inventory carrying cost efficiently. The researcher was given a three-year project to develop this model and implement the strategies. Before the implementation of this project, the case company was using servigistics inventory planning software for its spare parts inventory management. The software had several possible features that can be used to reduce excess stock (e.g., lateral transshipment policy, Croston forecasting for intermittent items) but have not been activated because adequate knowledge of how to do this and the underlying logic of the optimization in the software was lacking. The case study was conducted in three steps as shown in Figure 2 below.

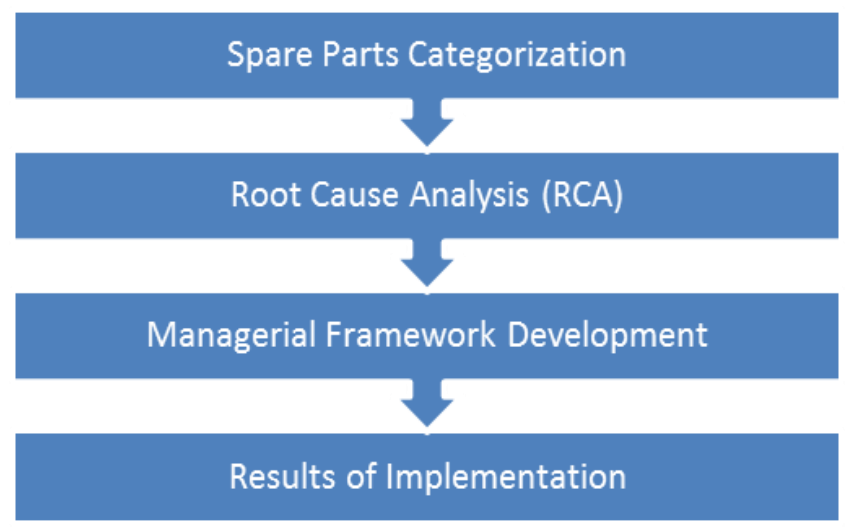

Figure 2 Case-based action research approach for the study

First, a description of the categorization of spare parts in the case organization is made to understand the nature of the spare parts and the challenges in managing the excess and dead inventory. Second, a Root Cause Analysis (RCA) is conducted to understand the root cause of excess and dead inventory for the case organization as suggested by Crandall and Crandall (2003). Root cause analysis is a set of tactics that can be applied to determine the underlying cause(s) of a problem as well as supporting management processes (Rooney \& Vanden, 2004; Tomic \& Spasojevic, 2011). The root cause analysis is valuable in informing a broader system-level understanding of recurring challenges of excess and dead inventory. The root cause analysis is described in more details in section 4.2. Third, the result of the root cause analysis is synthesized with the literature review and a managerial framework consisting of the suggestions from the literature review and novel ideas are presented. The framework is shown in Figure $\mathbf{7}$ and it is discussed in more details in section 4.3. Fourth, we discuss the implementation of the framework in the case organization and the results achieved after three years. This is discussed in section 4.3.14.3.3.

\section{RESULTS}

\subsection{Spare Parts Categorization}

Jouni, Huiskonen, and Pirttila (2011) undertook a study in 2010 that depicts the spare parts classification for the case company as shown in Figure 3.

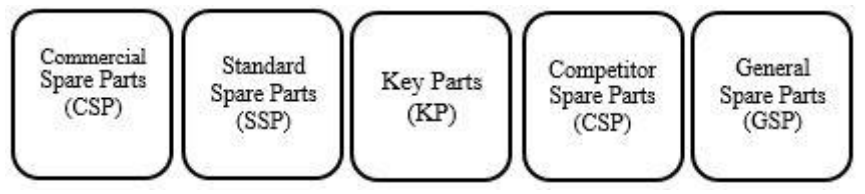

Figure 3 Spare parts categorization (Adapted and modified from Jouni et al., 2011)

Commercial spare parts are commercially available spare parts or component designed and produced outside of the case company. They are common bulk materials such as light bulbs, screws, and bolts and widely used across all industries and are available from several sources (Jouni et al., 2011). Key parts are spare parts designed and manufactured by the case company. They have only a few possible suppliers and are in most cases made-to-order parts, such as PCB boards or other electronic parts (Jouni et al., 2011). Standard Spare parts are industry specific parts that are commonly available within the elevator industry (Jouni et al., 2011). Competitor spare parts are specifically competitor's spare parts procured by the case company used to maintain competitor equipment's. Thus, they could by its nature be competitor key parts or standard parts. General spare parts are spare parts which are designed by the case company, but it is easy to copy, refabricate/backward engineer. Examples are push button base, pressels, switches, etc.).

The case company defines excess inventory as the stock quantity left in inventory after subtracting on-hand stock quantity from two years' consumption. Dead inventories are spare parts in inventory with at least two years of no demand. Figure 4 shows the categorization of the spare parts in the case company and the value of excess inventory. Thirty-four percent $(34 \%)$ of the total inventory value of the case company is in excess. That is, $15 \mathrm{M} €$ worth of inventory was in excess, and key spare parts, commercial spare parts, general spare parts, standard spare parts and competitor spare parts constituted $32 \%, 23 \%, 27 \%, 16 \%$, and $2 \%$ of total excess inventory value respectively. In terms of SKU's, about $36 \%$ of the SKU's had excess inventory.

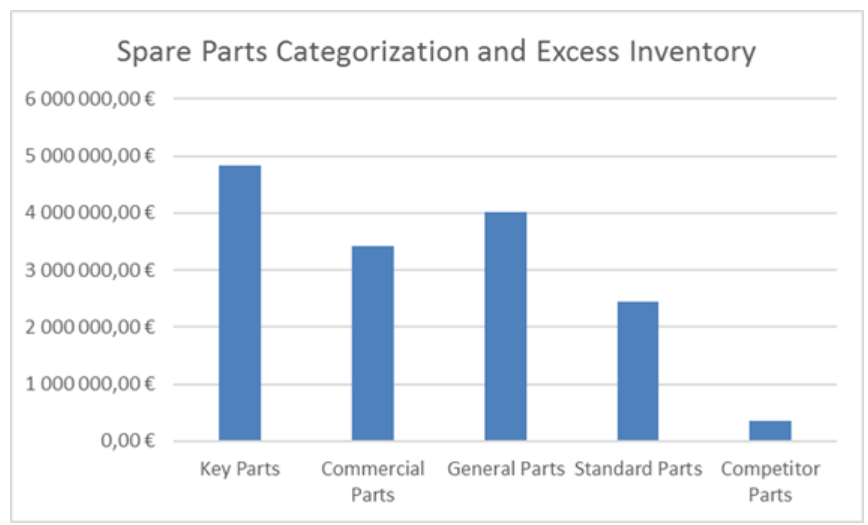

Figure 4 Spare parts categorization and excess inventory 
Several dissections were done for the excess inventory data to get a more in-depth glimpse of the excess inventory. Thus, year profiles, i.e., when they were created into the offering, and their dead stock value, was used to segment the data. Also, Figure 3 was segmented further into the elevator component material groups as shown in Figure 5.

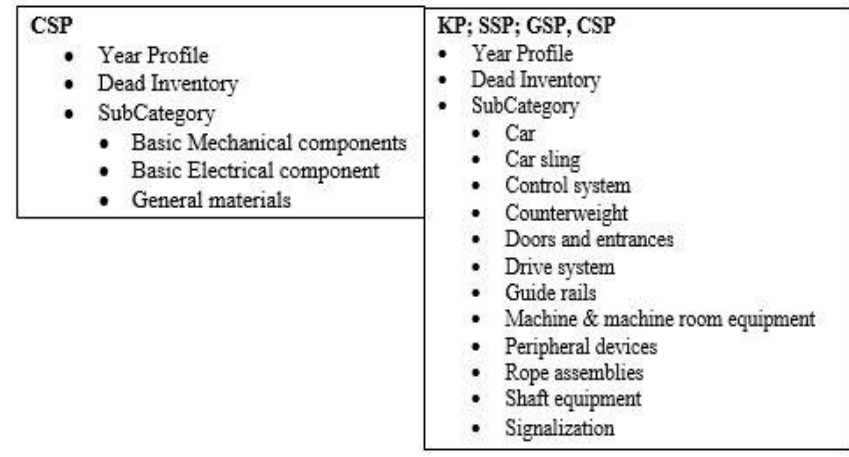

Figure 5 Sub segmentation of excess inventory for spare parts in elevator industry

From this segmentation, a clear understanding of the excess inventory became evident. First, the year profile showed a considerable value of excess inventory from spare parts introduced to the case company's offering in the year 2005 and these inventories had been dead inventories for ten years. These inventories worth 1,2M€ but the case company had spent 1,3M€ paying for warehousing for these inventories for ten years, thus paying more than the worth of the inventory. The findings from this categorization and the literature review gave inputs that were used to carry out root cause analyses discussed in the next section.

\subsection{Root Cause Analysis}

The root cause analysis revealed severe issues on how the case company had accumulated the much of excess inventory over the years. The result of the root cause analysis is shown in Figure 6 below.

First, the inventory planning team implemented a new software servigistics for the planning of their spare parts. It was noticed that errors in prices for example when the price of spare parts is missing, it automatically takes a value of 0.001 . As a result, the yearly carrying cost per unit becomes overblown in the traditional economic order model (EOQ), leading to excessive purchases. Also, there were errors in vendor minimum order quantities (VMOQ) for certain spare parts. These order quantities were set up for a specific supplier and not a vendor minimum order quantity, instead, a one-time sourcing request to acquire large quantities for a specific year to get discounts (sourcing savings). As demand trends downward as a result of the end of life-cycle, the VMOQ values are not updated leading to high excess inventories.

Second, it was evident that the introduction of new spare parts into offering had no proper logic for forecasting first order quantities. Instead, several technical support specialists randomly gave estimates of the initial quantity to purchase. In most cases, these quantities are high, and with less demand, they end up in excess inventory. Furthermore, it was evident that when materials are approaching obsolescence, the technical support specialist creates new replacement or alternative spare parts into their offering. Often, the replacement solutions have newer technologies with a lower price. For this reason, the demand for the new spare parts cannibalizes the demand for existing spare parts leading to excess inventory.

Third, with regards to demand forecasting, three specific issues were realistically the causes of excess inventory. First, there are specific projects-like specific spare parts, (project spare parts) for example, spare parts or component recall for newly installed equipment. It could also be a replacement of specific spare parts across several installed elevators were rather than planning this via direct ship/drop shipping the spare parts directly from suppliers to customers, they are planned as standard inventory SKU's. As a result, when the project comes to an end, there is excess inventory left because demand is planned according to the traditional inventory planning model where as soon as stock gets below the reorder point, EOQ is ordered. Second, Croston or SBA had not been implemented for the intermittent SKU's, and about $30 \%$ of the SKU's are intermittent. Intermittent items have been shown to have risks of obsolescence and the implementation of Croston/SBA forecasting method have been shown to reduce about $12 \%$ total inventory value (Boylan et al., 2008). Finally, maintenance equipment policy and data are currently not used in forecasting. Instead, forecasting is based on demand-based forecasting.

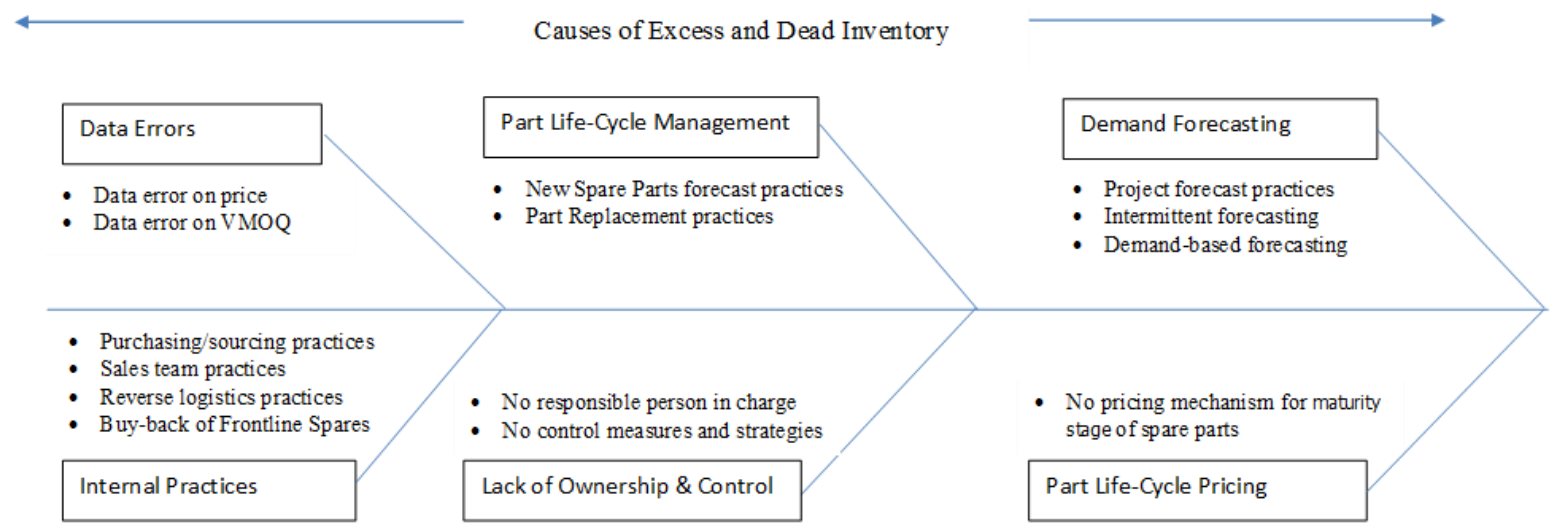

Figure 6 Cause and effect diagram : Causes of excess inventory in elevator industry 
The problem with this type of forecasting has been discussed in detail in the literature review.

Fourth, there were several internal practices at the organization that was also causing excess inventory. First, suppliers via sourcing/purchasing function are encouraging the business to buy large quantities and get discounts. While it helps in sourcing savings, when done uncontrollably, it results in excess inventory. For example, they were done for intermittent demand items. They use historical annual demand quantity to negotiate current year demand assuming a naïve forecast, i.e., last year's demand quantity will be same for the following year. Because of the infrequent demand intervals in intermittent SKU's, they often end up in excess inventory. The sales team often request safety inventories to be kept for key customers, and in some cases, these inventories are not sold and not monitored. Reverse logistics policy was lacking in the organization. Customer returns large quantities and value of spare parts they ordered wrongly, which the demand history has already been updated for forecasting, triggering large new EOQ's. By the time they are returned, the combined inventory from new EOQ and returned quantities sum up into excess inventory. The department made a strategic decision in the year 2005 to close subsidiaries warehouses in an aim to centralize the spare parts and warehousing unit. Most spare parts that existed at the subsidiaries were purchased back and kept in the centralized warehouse. No proper and exhaustive check was done about what these inventories where and what to take, dispose of, instead, all spare parts were purchased and transferred to the central warehouse. Most of these inventories still exist as excess inventories today.

Fifth, part life-cycle pricing was entirely missing in the case organization. Pricing in the case organization is based on the categorization discussed in Figure 3. The challenge with this model is that as a product moves from one stage in the part life-cycle to another, it is expected that organization should explore possible pricing changes. For example, key parts which are often more expensive than other spare parts, towards the end of the life-cycle (decline stage), third-party and competitors' solutions become available, yet the spare parts are still classified as key parts and priced accordingly.
For this reason, competitors and third-party providers start offering cheaper solutions putting pressure on the company's customers to start purchasing from the third-party providers/competitors leading to excess inventory for the case company.

Finally, one of the most important root cause of excess inventory for the case organization is that there was no ownership and someone responsible for controlling and managing excess inventory. The department had an inventory planning team but did not have any person responsible for managing and controlling excess inventory. Because of lack of ownership over the years, no one in the organization had complete knowledge of how, when and why the excess inventory had accumulated over the years. While traditional inventory management takes care of controlling, managing and ensuring spare part availability, reducing and controlling excess inventory requires ownership and strategic approach and the continuous implementation of novel strategies to keep the excess inventory to a bearable minimum. It is obvious that due to the nature of the elevator spare parts business, there will always be excess inventory. However, the excess inventory can always be kept in good control and to a bearable minimum.

\subsection{Model for Managing and Reducing Excess Inventory}

Figure 7 below shows a strategic model for managing and reducing excess inventory. We discussed in details how these strategies were implemented in the case organization and the results achieved within three years.

While Crandall and Crandall (2003) suggest a lifecycle approach to reducing excess inventory, i.e. a continuous operational process in the company, in the model above, it is suggested that a combination of strategic action, operational reactive and operational proactive measures are needed to control and reduce excess inventory for the elevator industry. A similar approach has been suggested for managing and reducing obsolescence (Sandborn, 2008).

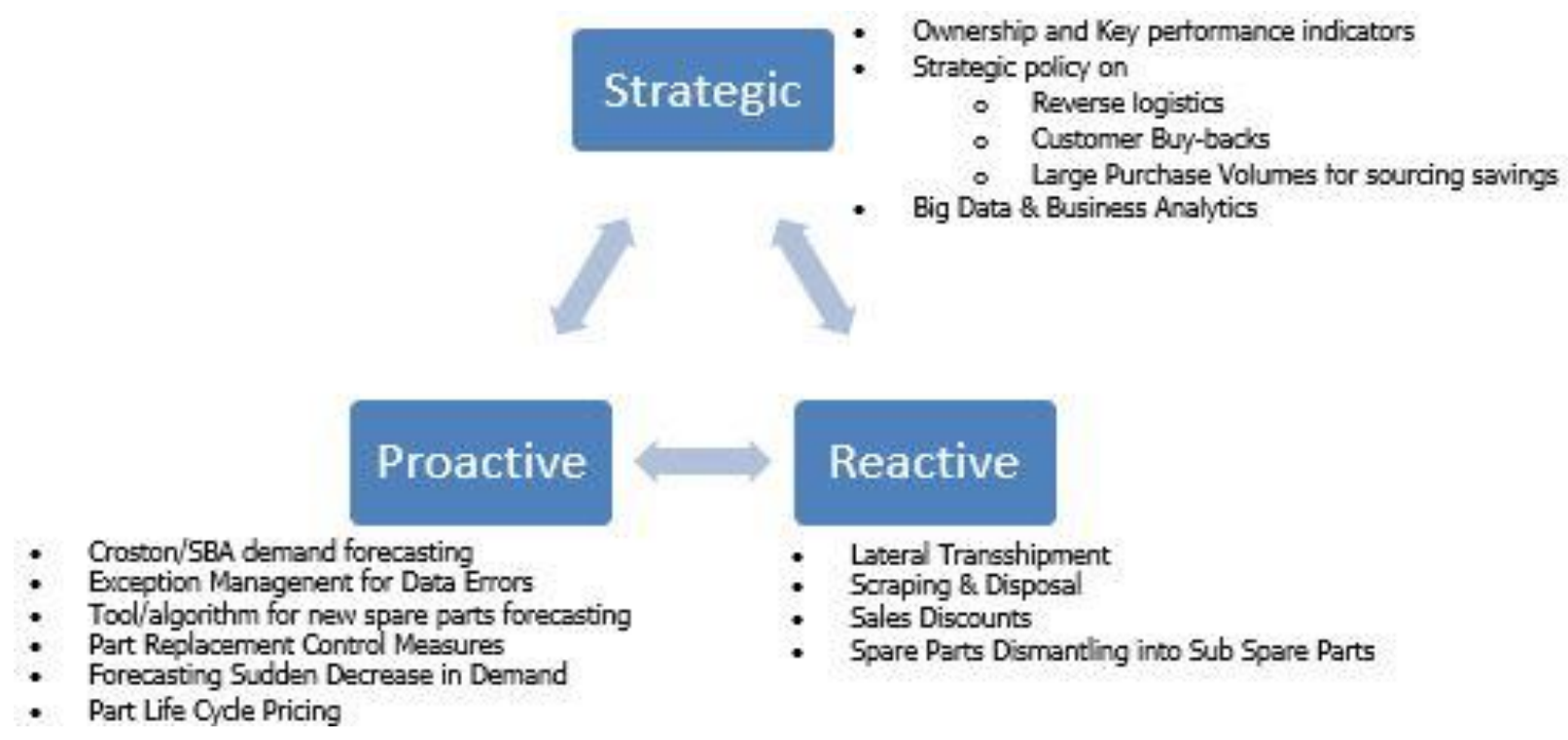

Figure 7 Tool-box for excess stock control and reduction in elevator industry 


\subsubsection{Strategic Response}

Strategic response requires a combination of ownership, policy, big data and business analytics. First, Ownership assigns responsibility to the inventory planning team to control, monitor and reduce the excess inventory to an agreed percentage value of excess annually. With this ownership, it is then possible to plan a mix of reactive and proactive actions to carry out yearly to accomplish the set goals. For the case organization, responsibility was given to the researcher to own the excess inventory reduction, and the annual reduction was set at $-500 \mathrm{~K} €$. The goals were achieved, and after three years, excess inventory was reduced by $-3 \mathrm{M} €(15 \mathrm{M} €$ to $12 \mathrm{M} €)$.

Second, it is essential that a clear policy is set up for issues affecting different functional teams. Internal organizational practices can only be tackled by clear set out organizational policy with top management approval. Policy on reverse logistics was amended such that items which are excess inventory are not accepted back under the new reverse logistics policy. Over a specific euro value with customer insistence, management approval is sought for, and customers are asked to scrap the inventory and receive a credit note worth $50 \%$ of the value of SKU purchased. Also, policy on customer buy-backs was established. Customer buy-backs is a process in which customer resale unused spare parts they initially purchased. The difference to reverse logistics policy is that items are accepted under reverse logistics if they have been purchased within a return warranty period of six months. After this period, they become part of customer buy-back process. Customer buyback process is important in spare parts business because OEM can purchase the same spare parts they usually purchase from suppliers at an even less price from a customer than the supplier offers. For customer buy-back cases, all SKU's in excess inventory and items with inventory levels up to one year demand are not accepted.

Big Data and Business Analytics open more strategic approach to managing and reducing excess inventory. During the first three years of implementation of this project, big data and business analytics aspect were not explored. In 2017, the researcher was assigned responsibility for big data in maintenance and spare parts business and leveraging the potential benefits of big data to excess spare parts reduction was a critical area under exploration. Three potential areas were under exploration and exploitation.

First, there is potential to link the spare parts to the actual equipment they can be used mainly for the equipment owned and maintained by the case company. Linkages were made for most of the valuable excess spare parts inventory to the actual equipment's they were designed to be used. Most of these elevators are owned by strategic customers and are in highly concentrated areas of the urban cities. Customers who owned the equipment were offered proximity storage location in customer premise for critical spare parts meant as strategic safety inventories in the event of equipment failure. This enables the case organization to sell some of the excess inventory and save storage cost while transferring the ownership and storage to the end customers.

Second, another important potential from big data is for commercial spare parts. With the millions of websites available on the web, it is possible to do data mining on the web and find potential buyers of commercial spare parts (e.g., screws, bolts, lights, bulbs, washers, etc.) and offer these excess inventories for sale. Finally, the case organization is currently developing capabilities to link equipment data to demand forecasting. As this is currently under development in the case organization, no details of how this is done will be elaborated for confidentiality reasons.

\subsubsection{Strategic Response}

Reactive response deals with determining, executing, tracking and documenting appropriate actions to the existing excess inventory. Four responses were taken as shown below:

- $\quad$ Lateral Transshipment

- Scraping \& Disposal

- $\quad$ Sales Discounts

- $\quad$ Spare Parts Dismantling into Sub Spare Parts

Lateral Transshipment policy was implemented for the case company. The inventory software already had this functionality but requires configuration and set-up for this to take effect. The software conceptualizes lateral transshipment as "balancing." The lateral transshipment checks other warehouse in the distribution chain with excess inventory as an alternative and priority to procuring spare parts, thereby reducing excess inventory as well as cost and time involved in stocking or replenishing parts. One challenge was that the algorithm utilized in the software does not correspond to the excess inventory conceptualization in the case organization. As a result, a configuration and new algorithm was needed. The simplistic model is below:

- $\quad$ Set warehouse with excess inventory as a priority for replenishing parts in the central warehouse.

- Excess inventory defined as SKU's with on-hand inventory exceeding latest two years demand

- $\quad$ Order EOQ from excess On-hand Inventory up to six months on-hand inventory considering location specific requirements

By applying this logic, minimum six-month on-hand inventory is left at the source location as buffer/safety levels for servicing customers in that region. If EOQ quantity exceeds the six months, the balance quantity is ordered directly from the supplier. This approach reduced excess inventory by $-350 \mathrm{k} €$ annually and $1 \mathrm{M} €$ over three years.

Scraping and disposal of excess inventory were implemented. However, this was done after a depth of analysis had been done. Priority was given to dead inventories worth $2 \mathrm{M} €$. For these inventories, the year profile and storage cost calculations revealed how long they have been dead inventories and how much have been spent on storage cost. Based on this, we marked SKU's on scrap and disposal priorities in a Linkert scale of 1-3 where three (3) indicates the highest priority items were storage cost had exceeded the value of the SKU. Linkert scale 2 and 1 indicate storage cost will exceed the value of the SKU's in next three years and over three years respectively. These inventories were further classified into recyclable items and broken down into various categories, for example, PCB's aluminum, etc. and others as shown below.

Commercial materials SKU's with significant sales discount potentials were promoted at discount prices to suppliers and external customers and thus excluded from the scrapping list. Also, spare parts with the possibility to dismantle into other sub spare parts in the offering were 
excluded from the list. When implemented, on average about $300 \mathrm{~K} €$ worth of inventory were scrapped and disposed of annually. For the recyclable items, some salvage value proceeds where paid back to the corporation.

Table 1 Scrapping and Disposal Priority List

\begin{tabular}{|l|l|}
\hline SKU Classification & $\begin{array}{l}\text { Scrapping \& Disposal } \\
\text { Priority (1-3) }\end{array}$ \\
\hline $\begin{array}{l}\text { Recyclable Spare Parts (e.g. PCB, } \\
\text { aluminum etc.) }\end{array}$ & \\
\hline Others & \\
\hline
\end{tabular}

Sales discounts were given to particular SKU's and commercial SKU's after conducting market intelligence. For this action, on average $250 \mathrm{~K} €$ annual reduction in excess inventory was recorded with sales impact of $600 \mathrm{~K} €$ in 3 years. Finally, spare parts dismantling into sub spare parts was implemented. The potential in this was estimated at over $1 \mathrm{M} €$. However, during this three years only $350 \mathrm{~K} €$ reduction in excess inventory had been achieved. Such an approach requires deep technical understanding and requires subcontracting to suppliers to dismantle the existing spare into sub spare parts.

\subsubsection{Proactive Response}

Proactive responses are actions taken to prevent excess inventory from accruing. This is a very useful way to prevent new excess inventory from materializing. This response was developed to tackle the root causes of excess inventory in the first place.

First, a tool with an algorithm for new spare parts introduction was developed. The tool provides demand forecast for all new spare parts introduced into the company. The algorithm combines customer forecast and "analogybased forecasting technique." Analogy-based forecasting technique derives a forecast for new spare parts based on demand pattern of a similar group of family of spare parts in the offering. This forecasting approach relies on innovation diffusion model (See Kurawarwala \& Matsuo, 1996; Hyndman \& Athanasopoulos, 2013; Pandey, Kumar \& Shrivastava, 2014). On the implementation of the new spare parts forecasting tool, the value of new spare parts with risks of accruing to excess inventory dropped from $2 \mathrm{M} €$ to $500 \mathrm{~K} €$ over three years.

Exception Management Triggers was created in the inventory planning tool to prevent purchasing for SKU's suspected to potentially have an error in pricing data and other inventory planning data to avoid excessive purchases. The tool recommends these SKU's daily and purchasers are able to review the source of the data errors, make a correction, refresh the tool and purchase the right economic order quantities. The implementation of the exception management trigger saw a whopping prevention of $100 \mathrm{~K} €$ from accruing to excess inventory within the first six months it was implemented.

Croston demand forecasting was implemented in the case organization. The specifics of this implementation and research was carried out as part of a thesis research project (See Oguji, 2013). Overall, the research showed that $28 \%$ of intermittent demand items end up as dead stock while $18 \%$ end ups as excess stock. Implementing Croston forecasting model reduced the pace at which intermittent demand spare parts end up as excess inventory.
Part life-cycle pricing model was recommended to the case company, but this has not been implemented completely. However, specific analysis of spare parts approaching their decline/end of life-cycle were recommended for price discounts. This action was combined with forecasting when there will be a sudden decrease in demand for specific spare parts. The result of forecasting sudden decrease in demand for the spare parts was used to rank SKU's on their excess risk profiles on a Linkert Scale 1-3. Items that will experience a sudden decrease in demand within the next two years are ranked with highest priority 3 , and next four years and after four years are ranked as 2 and 1 respectively. With this risk profile, it was then easy to prioritize and start proactive actions on this group of SKUs' to prevent future excess inventory from accruing.

Finally, measures were put in place in the case organization to control part replacement process to avoid cannibalization. For example, when creating new spare parts for replacing existing spares, the existing spare parts are either sold at discounted prices before the introduction of new spare parts or the new spare parts are not released for sales until existing spare parts are sold out or sold to a bare minimum inventory that corresponds to the lead time of procuring the new spares from the supplier. This action prevented the accruing of new excess inventory due to part replacement process.

\section{CONCLUSIONS}

This study focuses on managing and reducing excess inventories in the elevator industry through a combination of literature review and root cause analysis. Based on this, reactive, proactive and strategic recommendations were presented on how to practically reduce the stockpile of excess inventory in the elevator industry.

This paper has shown the root causes of excess inventory to include amongst others, both internal organizational practices and lack of strategic ownership and policy in inventory management practices. There are generic studies about managing excess inventory, but industryspecific approaches are limited. Different industries have different types of spare parts and are subject to varying lifecycle which impacts on how to manage its inventory as well as reducing its stockpile of excess inventories.

Explicitly, it was shown that the root cause of excess inventory in the elevator industry is because of data errors in inventory planning parameters, not applying appropriate demand forecasting methods, lack of ownership, lack of part life-cycle management and part life-cycle pricing as well as internal practices within the organizations that creates functional silos to satisfy a specific function/team performance.

This paper has shown practical and reliable approaches in which spare parts managers can utilize to reduce the stockpile of excess inventory. The tool-box suggested in this paper requires strategic approaches such as putting in place policy on internal practices on large volume purchase practices of the sourcing department as well as policies on reverse logistics and customer buy-backs. More so, the strategic response must leverage the potential of big data and business analytics in reducing excess and dead inventories. Finally, ownership of the inventory management function 
including key performance indicator for controlling, preventing and reduce excess inventories is required.

Several proactive and reactive strategies were recommended in this paper. Proactive responses include the application of suitable demand forecasting technique such as Croston/SBA for forecasting intermittent items, setting up of exception management triggers to prevent data errors leading to excess purchases. A proper and strategic approach to forecasting new spare parts introduced into the offering, controlling part replacement processes to prevent cannibalization of existing spares leading to excess inventory. More so, forecasting sudden decrease in demand and prioritizing high excess risk SKU's for proactive actions is vital for preventing spare parts from accruing to excess inventory. Furthermore, the use of risk profiles for spare parts approaching their end of the life-cycle and offering pricing discounts seemed an appropriate proactive strategy. With respect to reactive measures, lateral transshipment models, scrapping, and disposal of appropriate excess inventories after depth analysis, as well as offering sales discounts and spare parts dismantling led to a decrease of over $3 \mathrm{M} €$ worth of excess inventory in three years.

Managing excess inventory should be a strategic focus of the inventory planning or supply chain optimization function in the global distribution chain. It should be inculcated into or considered when introducing new spare parts into the offering and when introducing new inventory planning software. Specific algorithms might be configured/customized according to how firms conceptualize its excess inventory. If the approaches suggested in this paper is properly implemented, excess inventory can be reduced drastically especially in the elevator industry.

Theoretical, this paper contributes to research on managing multi-echelon spare parts supply chains (Porras \& Dekker, 2008; Jaarsveld and Dekker, 2011; Tiacci \& Saetta, 2011; Thormann, 2015; Zhao et al., 2016; Nakandala, Lau, \& Shum, 2017), however, extends it to the context of elevator industry. To the best of found knowledge, this is the first study to discuss excess inventory management and control in the elevator industry. Utilizing a case-base action research approach, in a case company, this study bridges the gap between research and practice by testing and applying theories developed in supply chain and inventory optimization literature in solving excess stock challenges in a case company. It is believed that the practice of operations and supply chain management can be enhanced by applying established and novel researches published in supply chain journals.

Big data is an emerging theme in operations and supply chain, and it shows promising opportunity in advancing research and the practice of operations and supply chain management. While recent reviews (e.g., Wamba, Akter, Edwards, Chopin \& Gnanzou, 2015) and studies (Chae, 2015) have shown this promising trend, big data in spare parts management will be an important area of research for spare parts management and control of excess inventory. Boone, Skipper, and Hazen (2017) have developed a framework for investigating the role of big data in service parts management, but empirical studies investigating these various themes are yet to be seen. Future studies should explore how big data can help in the planning and control of excess inventories.

\section{REFERENCES}

Aastrup, J. \& Halldorsson, A. (2008) Epistemological role of case studies in logistics A critical realist perspective. International Journal of Physical Distribution \& Logistics Management, 38(10), pp. 746-763.

Anthony, H (1973) Determination of Excess Stock Quantities Management Science, 19(12), pp. 1444-1453.

Boone, C. A., Skipper, J. B. \& Hazen, B. T. (2017) A framework for investigating the role of big data in service parts management. Journal of Cleaner Production, 153(1), pp. 687-691.

Brown, G.W., Lu, J.Y. and Wolfson, R.J. (1964) Dynamic modeling of inventories subject to obsolescence. Management Science, 11(1), pp. 51-63.

Chae, B. V. (2015) Insights from hashtag \#supplychain and Twitter Analytics: Considering Twitter and Twitter data for supply chain practice and research. International Journal of Production Economics, 165, pp. 247-259.

Crandall, R.E. and Crandall W. R. (2003) Managing excess inventories A life-cycle approach. Academy of Management Executive, 17(3), pp. 99-113.

Flyvbjerg, B. (2006) "Five misunderstandings about case-study research," Qualitative Inquiry, 12(2). pp. 219-45.

Harrison, T. P., Lee, H. L., \& Neale, J. J. (2004) In the Practice of Supply Chain Management-Where theory and application converge. International Series in Operations Research \& Management Science. New York: Springer.

Hyndman R.J, Athanasopoulos, G. (2013) Forecasting: principles and practice, otexts. https://www.otexts.org/book/fpp. (Accessed: 5 August 2017).

Jouni, P., Huiskonen, J., \& Pirttila, T. (2011) “Improving global spare parts distribution chain performance through part categorization." A Case Study. International Journal of Production Economics, 133(1), pp. 164-171.

Keizer, M. C. A. O., Teunter, R.H., Veldman. J. (2017) Joint condition-based maintenance and inventory optimization for systems with multiple components, European Journal of Operational Research, 257(1), pp. 209-222.

Kennedy, W.J., Patterson, J. W. \& Fredendall, L. D. (2002) An overview of recent literature on spare parts inventories, International Journal of Production Economics, 76(2), pp. 201-215.

Louit, D. Pascual, R. Banjevic, D. Jardine, A.K.S (2011) Condition-based spares ordering for critical components, Mechanical Systems and Signal Processing, 25(5), pp. 18371848.

Lyte B. (Flexport Report): How Are Planes Decommissioned, and how much value can be salvaged from their parts? https://www.flexport.com/blog/decommissioned-planessalvage-value/ (Accessed: 3 August 2017).

Matsuo, H. \& Kurawarwala, A. A. (1996) Forecasting and Inventory Management of Short Life-Cycle Products, Operations Research, 44(1), pp. 131-150.

Nakandala, D., Lau, H. \& Shum, P. K.C. (2017) A lateral transshipment model for perishable inventory management, International Journal of Production Research, 55(18), pp. $5341-5354$

Oguji, N. (2013) Forecasting for intermittent spare parts in singleechelon multi-location and multi-item logistics network: Case KONE Global Spares Supply. Unpublished Aalto University Master's Thesis. https://aaltodoc.aalto.fi/handle/123456789/19794\#filessection

Olsson, F. (2010) An inventory model with unidirectional lateral transshipments, European Journal of Operational Research 200(3), pp. 725-732.

Pandey, P. Kumar, S. \& Shrivastava, S. (2014) A unified strategy for forecasting of a new product, Decision 41(4), pp. 411-424.

Paterson, P.C., Kiesmuller, G., Teunter, R., Glazebrook K., (2009) 
"Inventory Models with Lateral Transshipments: A review". Repository books. Lancaster University Management School, Lancaster.

Poppe, J., Basten R.J.I., Boute, R.N. Lambrecht, M. R. (2017) Numerical study of inventory management under various maintenance policies. Reliability Engineering and System Safety Article in Press, 1-12.

Porras, E. \& Dekker, R. (2008) An inventory control system for spare parts at a refinery: An empirical comparison of different re-order point methods, European Journal of Operational Research, 184(1), pp. 101-132.

Prince, C. \& Dekker, R. (2011) An inventory model for slowmoving items subject to obsolescence, European Journal of Operational Research, 213(1), pp. 83-95.

Rooney J. J, Vanden Heuvel L. N (2004) Root cause analysis for beginners, Quality Progress, 37(7), pp. 45-53.

Sandborn, P. (2008) "Strategic Management of DMSMS in Systems," DSP Journal, April/June, pp. 24-30.

Sandborn, P. (2013) Design for obsolescence risk management. 2nd International Through-life Engineering Services Conference, Procedia CIRP 11, pp. $15-22$.

Sarker, R. \& Haque, A. (2000) Optimization of maintenance and spare provisioning policy using simulation, Applied Mathematical Modelling, 24(10), pp. 751-760.

Silver, E. A \& Willoughby, K. A. (1999) Disposal of excess stock at the end of a project when facing on-going operational usage, International Journal of Production Economics 59(13), pp. 189-194.

Song, J-S \& Zipkin, P.H (1996) Managing Inventory with the Prospect of Obsolescence Operations Research, 44(1), pp. 215-222.

Srinivasan, S. R. Ramakrishnan, S. \& Grasman S. C (2005) identifying the effects of cannibalization on the product portfolio, Market Intelligence \& Planning 23(4), pp. 359-371.

Swanson, D.A., Tayman, J., Bryan, T.M (2011) MAPE-R: A Rescaled Measure of Accuracy for Cross-sectional Forecasts. http://cssd.ucr.edu/Papers/pdf (Accessed: 3 August 2017).

Sweeney, E., Grant, D. B., Mangan, D. J. (2015) "The implementation of supply chain management theory in practice: an empirical investigation", Supply Chain Management: An International Journal, 20(1), pp. 56-70.

Syntetos, A.A. \& Boylan, J.E. (2005) "The Accuracy of Intermittent Demand Estimates", International Journal of Forecasting, 21(2), pp. 303-314.

Syntetos. A. A. \& Boylan, J. E. (2006) "On the stock-control performance of intermittent demand estimates", International Journal of Forecasting, 103(1), pp. 36-47.

Syntetos, A.A. \& Boylan, J.E., \& Croston, J.D. (2005) "On the categorization of Demand" Journal of the Operational Research Society, 56(5), pp. 495-503.

Syntetos, A. A., Babai, M. Z., Dallery, Y., \& Teunter, R. (2009) "Periodic Control of Intermittent demand items: theory and Empirical Analysis", Journal of the Operational Research,
60(5), pp. 611-618.

Teunter, R, H., Syntetos, A. A., \& Babai, M. Z. (2011) "Intermittent Demand: Linking Forecasting to Inventory Obsolescence", European Journal of Operational Research, 214(3), pp. 606615 .

Thormann (2015) Integration of Real-Time Demand Information and Spare Parts Distribution Planning for the Optimization of Spare Parts Supply in After-Sales Service Networks, Operations and Supply Chain Management: An International Journal, 8(1), pp. 1 - 10.

Toelle, R. A \& Tersine, R. J. A (1992) Dynamic Programming Method for Determining Optimum Liquidation Quantities for Slow-Moving Inventories. Computers and Industrial engineering 22(3), pp. 353-358.

Toelle, R. A \& Tersine, R. J. A (1984) optimum Stock Levels for Excess inventory items, Journal of Operations Management, 4(3), pp. 245-258.

Tomic B, Spasojevic Brkic V. (2011) Effective root cause analysis and corrective action process. Journal of Engineering Management and Competitiveness, 1(1/2),16-20

Teunter, R, H., Syntetos, A. A., \& Babai, M. Z. (2011) "Intermittent Demand: Linking Forecasting to Inventory Obsolescence", European Journal of Operational Research, 214(3), pp. 606615.

Tiacci, L., \& Saetta, S. (2011) "Reducing the mean supply delay of spare parts using lateral transshipments policies" International Journal of Production Economics, 133(1), pp. 182-191.

Van Horenbeek A, BuréJ, Cattrysse D, Pintelon L, and Vansteenwegen P. (2013) Joint Maintenance and inventory optimization systems: a review, International Journal of Production Economics, 143(2), pp. 499-508.

Wamba, S. F., Akter, S., Edwards, A., Chopin, G, \& Gnanzou, D. (2015) How 'big data' can make big impact: Findings from a systematic review and a longitudinal case study, International Journal of Production Economics, 165, pp. 234-246.

Wang, W. \& Syntetos, A. A. (2011) Spare parts demand: Linking forecasting to equipment maintenance, Transportation Research Part E, 47(6), pp. 1194-1209.

Zahedi-Hosseinia, F., Scarf. P., \& Syntetos A. (2017) Joint optimization of inspection maintenance and spare parts provisioning: a comparative study of inventory policies using simulation and survey data, Reliability Engineering and System Safety, 168, pp 306-316.

Zhao, F. Wu, D., Liang, L. \& Dolgui, A. (2016) Lateral inventory transshipment problem in online-to-offline supply chain, International Journal of Production Research, 54(7), pp. 1951-1963.

Zohrul Kabir A, Al-Olayan A.S (1996) A stocking policy for spare part provisioning under age based preventive replacement, European Journal of Operation Research, 90(1), pp. 171-81.

Dr. Nnamdi Oguji is an experienced professional with more than five years' industrial experience working as a Business Analyst and implementing global supply chain projects for KONE Finland. Nnamdi is also an international business researcher with a PhD in International Business and Marketing from the University of Vaasa in Finland. Nnamdi's research interest span across thematic areas in international business, supply chain management and Big Data. 